\title{
Anode Materials for Rechargeable Li-Ion Batteries
}

\author{
DE-FG03-00ER15035
}

\section{Progress Report \\ (covering work through Jan 15, 2001 to Nov. 18, 2001)}

\author{
for the \\ U. S. Department of Energy \\ Office of Basic Energy Science \\ Division of Chemical Sciences \\ from \\ Brent Fultz \\ Keck Laboratory of Engineering Materials 138-78 \\ California Institute of Technology \\ Pasadena, California 91125 \\ fax: $626795-6132$
}




\section{Abstract}

We have been performing basic materials science research on materials for anodes and cathodes in electrochemical cells. The work is a mix of electrochemical measurements and analysis of the materials by transmission electron microscopy and x-ray diffractometry. At present, our experimental work involves only materials for Li storage, but we have been finishing papers from our previous work on hydrogen-storage materials.

\section{Facilities and Personnel}

Our 8-channel Arbin cycler is now in regular operation with coin cells that we assemble in our glove box at Caltech. We have operated this cycler with coin cells containing Kapton x-ray windows, performing automated in-situ x-ray diffractometry on cathode materials. Results, shown in Fig. 1, are quite encouraging. Individual diffraction patterns were acquired in 5 minutes each. In the next few months we have planned an in-situ study on strains in cathode materials, and we are considering a study on anode materials made of nanocrystalline $\mathrm{Sn}$.

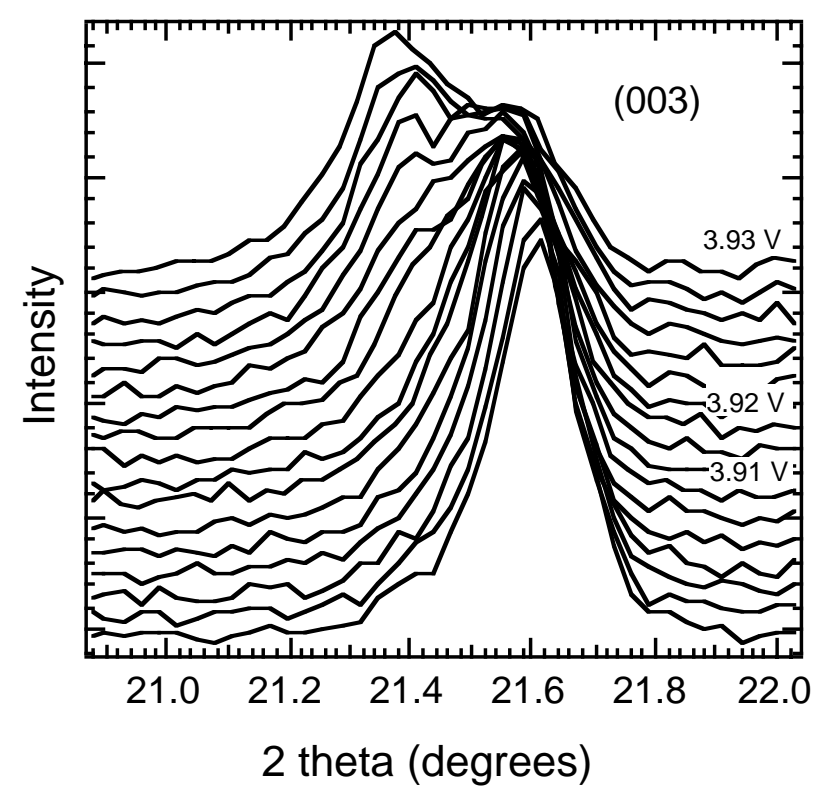

Figure 1. Enlargement of x-ray diffraction patterns of $\mathrm{LiCoO}_{2}$ showing only a diffraction from the basal planes. Diffraction patterns were acquired in 5 minutes each at various states of charge, labeled by voltage with respect to Li. Data acquisition is under full computer control.

Personnel supported on this grant include Dr. Heike Gabrisch, a postdoctoral fellow working on the TEM imaging research, Mr. Jason Graetz, a graduate student in materials science working on the EELS spectroscopy of electrode materials, Adam Wise, a first-year graduate student in materials science (largely on fellowhip support), and Yvan Reynier and Yasanori Ozawa, special 
students from Grenoble France partly supported from other funds. These special students are supervised in part by Dr. Rachid Yazami (arguably the inventor of intercalated graphite for Li batteries), who is spending a 2 year sabbatical at Caltech away from his position at CNRS in Grenoble. It has been a real joy working with Rachid. He is a continuous fountain of ideas, but we serve to filter them.

Prof. Peter Rez, a theoretical physicist at Arizona State University, has become wellintegrated with the laboratory research. Peter has performed electronic structure calculations to help us interpret TEM images as well as spectroscopic measurements on $\mathrm{LiCoO}_{2}$.

\section{Research Results}

\section{Dislocations in $\mathrm{LiCoO}_{2}$}

We performed a TEM study to understand the dislocations in $\mathrm{LiCoO}_{2}$. We found perfect dislocations, which had been suggested previously, and determined their character and Burger's vector, a new result. We also discovered Shockley partial dislocations in the layered structure of $\mathrm{LiCoO}_{2}$. These suggest that the energy to induce faulting in the layered $\mathrm{LiCoO}_{2}$ is not large. Faulting suggests possible damage mechanisms in this material, and suggesting the existence of other structures that would be difficult to identify by x-ray diffractometry.

We are now studying $\mathrm{LiCoO}_{2}$ that has been subjected to extensive electrochemical cycling.

\section{$\mathrm{New} \mathrm{LiC}_{10}$ and $\mathrm{LiC}_{8}$ structures in chemically lithiated single wall carbon nano tubes}

Single walled carbon nanotubes were reacted with molten lithium at $220^{\circ} \mathrm{C}$ for two weeks. Xray and TEM investigations indicate that a significant fraction of the initial SWNTs transformed from cylindrical carbon nanotubes to flat nanostrips having intercalated lithium in between them. The lithium atoms form a superlattice commensurate with that of graphite-like nanostrips with $\mathrm{a}_{0} \sqrt{7} \times \mathrm{a}_{0} \sqrt{3}$ in-plane distribution. This new structure corresponds to the $\mathrm{LiC}_{10}$ composition. $\mathrm{A}$ minor phase of $\mathrm{LiC}_{8}$ was also detected by TEM-diffraction.

We might continue work to assess how the presence of chirality in the SWNTs, identifiable in electron diffraction patterns, affects the unzipping of the tubes during lithiation.

\section{EELS of $\mathrm{Li}(\mathrm{Ni}, \mathrm{Co}) \mathrm{O}_{2}$ Cathodes -- Electronic structure}

Using electron energy loss spectrometry in the TEM, we have measured the changes during delithiation of $\mathrm{Li}(\mathrm{Ni}, \mathrm{Co}) \mathrm{O}_{2}$ in EELS spectra of the $\mathrm{Ni}$ and $\mathrm{Co} \mathrm{L}_{2,3}$-edges and the $\mathrm{O} \mathrm{K}$-edge. The $\mathrm{O}$ $\mathrm{K}$-edge shows a distinct pre-peak associated with unoccupied orbitals. The intensity of this prepeak is filled as $\mathrm{Li}$ is added to the material, indicating that there is a transfer of electron from $\mathrm{Li}$ to the $\mathrm{O}$. The changes are smaller at the $\mathrm{Ni}$ and $\mathrm{Co} \mathrm{L}_{2,3}$-edge. In collaboration with Peter Rez, we have found that the Li electron is accommodated primarily by the $\mathrm{O} 2 \mathrm{p}$ states, not states at the Ni or Co atoms. Over the past few weeks, it has begun to seem particularly likely that the valence of the $\mathrm{Ni}$ atoms, as for the Co atoms, is not changed significantly by Li insertion into $\mathrm{Li}(\mathrm{Ni}, \mathrm{Co}) \mathrm{O}_{2}$. 
As part of this effort, we have been measuring EELS spectra on standard samples of Li compounds such as Li halides. We have completed a study on $\mathrm{LiF}, \mathrm{LiCl}$, and $\mathrm{LiBr}$, and found a good correlation between the Li edge shifts and the electronegativity of the halide.

\section{Entropy of the Li-C system}

The open-circuit voltage and its temperature dependence were measured on half-cells with graphite electrodes in varying states of lithiation. These data were used to determine the entropy and enthalpy of formation of graphite intercalation compounds with different Li concentrations. The results were more interesting than expected and are being repeated. It is clear that the entropy of formation changes sign from positive to negative between low and high $\mathrm{Li}$ concentrations. Evidently the large configurational entropy at low concentrations gives way to low vibrational entropy at higher concentrations. Both the entropy and enthalpy tend to follow the staging of the intercalation compounds.

\section{Mechanism of self-discharge (collaboration)}

This study is perhaps better regarded as an extension of effort begun by Rachid Yazami when he was in Grenoble. A set of fully-charged coin cells were stored at elevated temperatures, and their capacity losses were determined. Nearly all the loss was reversible, at least for temperatures below about 70C. It is plausible that the reversible capacity loss involves an intermediate complex in the SEI that dissociates upon recharging the cell. The irreversible loss may correspond to more stable Li compounds in the SEI.

\section{Distributions of Hydrogen and Strains in $\mathrm{LaNi}_{5}$ and $\mathrm{LaNi}_{4.75} \mathrm{Sn}_{\mathbf{0 . 2 5}}$}

We completed a long-delayed study of hydrogen distributions and internal strains that accompany hydriding in binary $\mathrm{LaNi}_{5}$ and $\mathrm{LaNi}_{4.75} \mathrm{Sn}_{0.25}$. Small-angle neutron scattering showed that the distribution of deuterium in partially-deuterated $\mathrm{LaNi}_{4.75} \mathrm{Sn}_{0.25}$ is more homogeneous than in partially-deuterated $\mathrm{LaNi}_{5}$, at least on the spatial scales around $100 \AA$. It is suggested that the more homogeneous deuterium distribution in $\mathrm{LaNi}_{4.75} \mathrm{Sn}_{0.25}$ suppresses the strain gradients that cause decrepitation of the metal hydride. (It is known that the cycle life of the $\mathrm{Sn}$-containing alloy is superior to that of binary $\mathrm{LaNi}_{5}$ in both gas-phase and electrochemical cycling.)

\section{Plans for 2002}

We plan to use our new capability for in-situ x-ray diffractometry work of operating cells for a comparative study of cathode materials. The cathodes will be in two types of batteries:

1. Thin film solid state cells with $\mathrm{Li}(\mathrm{Ni}, \mathrm{Co}) \mathrm{O}_{2}$ cathodes, fabricated by our colleagues at JPL.

2. Coin cells with $\mathrm{Li}(\mathrm{Ni}, \mathrm{Co}) \mathrm{O}_{2}$ cathodes fabricated at Caltech The purpose of this study is to determine how the internal stresses differ in solid-state and conventional batteries. Its other purpose is to give us experience with the in-situ diffraction method. Although it is clear that this method can be used to determine the presence of different crystal structures in electrode materials, and has been used for this purpose by several groups, it is less clear if the data are of sufficient quality for quantitative measurements of the strain and size broadenings of x-ray diffraction peaks. 
Following our work on characterizing dislocations in $\mathrm{LiCoO}_{2}$, we have begun a TEM imaging study on heavily-cycled $\mathrm{LiCoO}_{2}$. The results so far do not show significant differences in the defect structures after cycling, somewhat to our surprise. On the other hand, the cycled mateirals show a considerable amount of $\mathrm{Co}_{3} \mathrm{O}_{4}$. From imaging and diffraction analysis we expect to learn more about how this phase is formed, and more about the transformation from hexagonal $\mathrm{LiCoO}_{2}$ to the cubic spinel.

The TEM EELS spectroscopy work is building towards using the energy shifts of the Li Kedge and metal edges to determine the chemical potential of the Li atom. It appears that the characteristic energy of the edge corresponds to the chemical potential of the $\mathrm{Li}$ atom, but this will likely have to be checked for each material of interest. To begin, we will acquire spectra on bulk samples of a few more lithium - transition metal oxides, perhaps with cubic spinel and hexagonal crystal structures. The plan is to test how the transition metal affects the edges. The benefit of using lithium - metal oxides is that there are numerous stable materials (many of which we have already measured). The metal ions range across the periodic table from $\mathrm{LiTiO}_{2}$ to $\mathrm{LiGaO}_{2}$. Similar studies may be performed on anode materials such as $\mathrm{Li}-\mathrm{Cu}-\mathrm{Sn}$ and $\mathrm{Li}-\mathrm{Zn}-\mathrm{N}$ with different amounts of Li.

Finally, we will continue to measure the temperature-dependence of the open circuit voltage of coin cells at various states of charge. We were surprised by the ease of acquiring good thermodynamic information from temperature-dependent studies of a single coin cell. Our first measurements on a graphite anode in a half-cell with a Li counter electrode will be repeated. These data showed clear changes of the entropy of formation at different stages of the intercalation process. For comparison, we will perform similar measurements on a half-cell with graphite of lower crystalline quality, to test the trends of entropy and enthalpy when staging is absent or less well defined. 


\section{Publications acknowledging support of this grant (either published in 2001 or submitted in 2001)}

1. R. Yazami, H. Gabrisch, and B. Fultz, "Self-organised carbon nanostrips with a new $\mathrm{LiC}_{10}$ structure derived from carbon nanotubes", J. Phys. Chem. B, in press.

2. J. Graetz, A. Hightower, C. C. Ahn, R. Yazami, P. Rez and B. Fultz, "Electronic Structure of Chemically-Delithiated $\mathrm{LiCoO}_{2}$ Studied by Electron Energy Loss Spectrometry", J. Phys. Chem. B, in press.

3. H. Gabrisch, R. Yazami, and B. Fultz, "The Character of Dislocations in $\mathrm{LiCoO}_{2}$ ", Electrochemical and Solid State Lett., submitted.

4. R. C. Bowman, Jr., and B. Fultz, "Gas Phase Applications of Metallic Hydrides," L. Schlapbach and R. W. Cahn, eds., MRS Bulletin, submitted.

5. B. Fultz, C. K. Witham, and T. J. Udovic, "Distributions of Hydrogen and Strains in $\mathrm{LaNi}_{5}$ and $\mathrm{LaNi}_{4.75} \mathrm{Sn}_{0.25}$ ", J. Alloys and Compounds, in press.

6. A. Hightower, C. C. Ahn and B. Fultz "Electron Energy Loss Spectrometry on Lithiated Graphite" Microbeam Analysis 2000; Institute of Physics Conference Series 165 (2000) pp. 225-226.

7. J. Graetz, R. Yazami, C. C. Ahn, P. Rez, and B. Fultz, "Electronic Structure of Oxygen in Delithiated LiTMO 2 Studied by Electron Energy-Loss Spectrometry", Proceedings of NATO-ASI New Trends in Intercalation Compounds for Energy Storage 2001, edited by C. Julien (Kluwer Press, 2001), submitted.

8. J. Graetz, A. Hightower, C. C. Ahn, P. Rez, and B. Fultz "Electronic structure analysis of $\mathrm{LiCoO}_{2}$ using electron energy loss spectroscopy (EELS)", Microscopy and Microanalysis Proceedings 2001 Vol. 7, edited by G. W. Bailey, R. L. Price, E. Voeikl, and I. H. Musselman (Springer, 2001) p. 1186-1187.

9. H. Gabrisch, R. Yazami, and B. Fultz, "Lattice Defects in $\mathrm{LiCoO}_{2}$ ", Microscopy and Microanalysis Proceedings 2001 Vol. 7 , edited by G. W. Bailey, R. L. Price, E. Voeikl, and I. H. Musselman (Springer, 2001) p. 518-519.

10. H. Gabrisch, R. Yazami, and B. Fultz, "Electron Diffraction and X-Ray Studies of New $\mathrm{LiC}_{10}$ and $\mathrm{LiC}_{8}$ Structures in Chemically Lithiated Single Wall Carbon Nanotubes," Proceedings of the 200th Meeting of The Electrochemical Society, San Francisco, Oct., 2001, in press.

11. J. Graetz, A. Hightower, C. C. Ahn, R. Yazami, P. Rez, and B. Fultz, "Electron Energy-Loss Spectrometry and Mapping of Oxygen in Delithiated $\mathrm{LiCoO}_{2}$ ", Proceedings of the 200th Meeting of The Electrochemical Society, San Francisco, Oct., 2001 , in press.

12. Yvan Reynier, Brent Fultz and Rachid Yazami, "Thermodynamics and kinetics of selfdischarge in graphite-lithium electrodes" Proc. 17th Annual Battery Conference on Applications and Devices, Long Beach, CA, January, 2002, E. T. Seo, ed., (Inst. Electrical Electronic Engs., Piscataway, NJ), submitted. 


\section{Graduate Students supported under this grant}

Yvan Reynier, special student at Caltech, graduate student at CNRS, Grenoble.

Adam Wise, Materials Science, Ph.D. expected: 2005 (mostly external fellowship support)

Olivier Delaire, Materials Science, Ph.D. expected: 2004

Jason Graetz, Materials Science, Ph.D. expected: 2002

Other personnel supported by this grant in 2000 have been:

Prof. Brent Fultz, Professor of Materials Science, Caltech

Dr. Heike Gabrisch, Postdoctoral Scholar, Caltech

Dr. Rachid Yazami, Visiting Associate in Materials Science, Caltech

\section{Funds}

Our bookkeeping shows that there will be no carryover of funds into the next year of the grant. 